\title{
EVALUATING VISUAL DISPLAY DESIGNS IN VEHICLES: ADVANTAGES AND DISADVANTAGES OF THE OCCLUSION TECHNIQUE
}

\author{
Josef F. Krems ${ }^{1}$, Andreas Keinath ${ }^{1}$, Martin Baumann, ${ }^{1}$, Christhard Gelau ${ }^{1}$, \\ KlausBengler $^{2}$ \\ 1 Chemnitz University of Technolgy, GERMANY \\ krems@phil.tu-chemnitz.de \\ 2 BMW AG, Munich, GERMANY \\ bengler@bmw.de
}

\begin{abstract}
Over the last few years the amount of in-car visual displays has steadily increased. Despite of positive aspects of additional systems it is important to make these systems as safety as possible. A method to evaluate the design objectives of quick and reliable information acquisition is the occlusion technique. In this paper we describe the technique and report experimental results from several evaluation studies. We found that the occlusion technique reliably discriminates between simple and complex visual displays. We also found that the occlusion technique reliably discriminates between dialogues that facilitate resumption after an interruption and those that do not. The implications of these results and the applicability of the method are discussed.
\end{abstract}

\section{INTRODUCTION}

New information and communication technologies for in-vehicle use are more and more available with an enhanced functionality also for use while driving. The object and advantage of these aids is increased convenience and operating safety, as demonstrated e.g. by the route guidance (navigational) systems. This development may have many positive aspects, but the question remains as to whether the "information overload" on the driver is increased by new, additional systems, thus having negative effects on traffic safety. It is well established that problems and errors in perception and vehicle-handling increases with the amount of mental workload (Dewar, 1988). The urgency of evaluating the advantages and disadvantages of driver assistance and navigation systems is therefore hard to ignore.

The main goal when developing and designing information systems should be the acquisition of information quickly and safely without distracting from the primary driving task. This principle is consequently laid down in the "European Statement of Principles" concerning the human-machine interface (HMI) for onboard information and communication systems (European Commission, 1998) as 
follows: "Visually displayed information should be such that the driver can assimilate it with a few glances which are brief enough not to adversely affect driving." To achieve this goal methods and tools are necessary for developers with which visual display design concepts can be evaluated even in the early design stages. One such procedure is the occlusion technique, which we have assessed for its validity and applicability in a series of display evaluation experiments.

The aim of this paper is to describe the occlusion technique as an evaluation instrument during the design process, and to give a summary of experimental results from several evaluation studies.

\section{TECHNIQUES TO EVALUATE VISUAL DISPLAYS}

The question of evaluating visual displays has been a topic of research for some time now and has led to many design principles being documented in literature (see e.g. Helander, 1987; Woodson, Tillmann and Tillmann, 1992). For our purposes, criteria that are intended to guarantee an effective flow of information to the driver are the most interesting. For example, Kantowitz and Sorkin (1983) propose visibility, distinguishability and interpretability of the information as criteria for evaluating displays. Speed and accuracy of information acquisition, the effort needed to become familiar with the system and several strain factors are to be tested in addition. Another very important design principle which is tailored specifically to the situation in a vehicle, and which plays an important role here, is the requirement that, from the safety standpoint, looking away from the road for longer than 2 seconds is unacceptable (see Zwahlen, Adams and DeBald, 1988; Färber, 1990). This time limit is also important from another point of view. Since increasingly complex displays such as e.g. navigational systems are now available, one must ensure that the dialogues initiated by these systems are easy to interrupt or can be easily continued after an interruption (see Leiser 1994; Ashby and Parkes, 1993). This demand is important, since dialogues that can be continued after an interruption (looking back at the road) make it easier for the driver to concentrate on his or her primary task of driving in critical situations. If this design rule is disregarded, the driver could remain occupied with the dialog task for too long and not pay enough attention to actual driving (see Antin, 1993).

The occlusion technique offers an opportunity to evaluate visual displays according to the three criteria mentioned above. Consideration of the "maximumtime to be tolerated" design principle is guaranteed by the very character of this technique. It is based on systematic control of the time intervals permitted for a person to look at a sample. The period during which the relevant piece of information is visible (viewing or presentation time) and the period during which it is not visible (occlusion time) are both controlled. The subjects can themselves determine how long they need to gather all the information without errors and set the time required as a standard. In addition, the relevant information can be presented within a limited period of time and the accuracy and quality of the information gathered can be used as a dependent variable. It is also possible to use the occlusion phase, i. e. the period during which the primary task is invisible, for working on other tasks in order to increase the ecological validity of the results. The basic method is thus related to tachistoscopic techniques in its basic approach which were 
used even in early examinations of the readability of different types of displays (e.g. Sleight, 1948).

\section{VALIDATION OF THE OCCLUSION TECHNIQUE}

The main goal of our experimental studies is to validate the occlusion technique as a tool for evaluating visual displays. A basic requirement for an evaluation tool implies that it discriminates between tasks of different complexity. Reliable differences between the performances of simple as opposed to complex samples have to be found so that the technique can be used as a "quick-and-dirty" evaluation method in the early design stages. Furthermore, the method should indicate how easy it is to interrupt various types of dialogues and how difficult it is to continue a dialogue after an interruption. In this section of the paper a summary of results from experimental studies will be given. For more details see Gelau et al. (1999) and Krems et al. (2000).

\subsection{Simple vs. complex examples for pre-defined presentation periods}

An initial series of experiments was conducted to explore how well the occlusion technique distinguishes between display versions with different design complexities. For the easier task, simple recall was sufficient in order to solve the reading task correctly while in the more complex version an additional comparing operation involving more effortful cognitive processes had to be carried out.

Stylised maps were displayed on a computer monitor (see Figure 1). For the simpler tasks, the subjects $(n=20)$ had to indicate by pressing a button which of two paths connected point $A$ with point $B$. In the complex version, three paths starting at A were displayed. The task was to identify the shorter of two ways connecting $A$ to $B$ and to press the associated direction key. The complex version called for the whole display to be searched completely and an additional cognitive comparison made. There was only one correct solution in both cases.

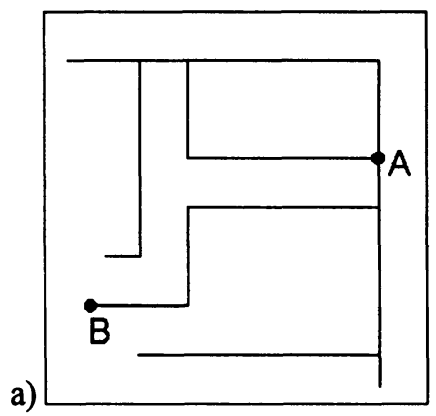

b)

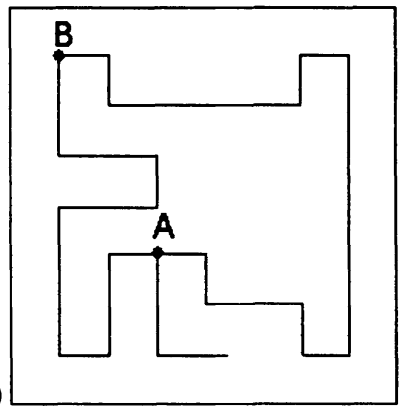

Figure 1: Display for the a) simple condition and b) complex condition. 
Independent variables were the presentation time (200 - 1200 milliseconds/ 8 stages) and the complexity of the task (simple vs. complex). Error frequency was chosen as a dependent variable.

As can be seen in Table 1, the probability of errors for the complex task was above that for the simple task for all presentation periods. The probability of mistakes in both conditions diminished when the presentation time was increased.

Table 1- Probability of errors for the simple and complex conditions.

\begin{tabular}{|l|l|l|l|l|l|l|l|}
\hline & $\begin{array}{l}200 \\
\text { msec }\end{array}$ & $\begin{array}{l}350 \\
\text { msec }\end{array}$ & $\begin{array}{l}500 \\
\text { msec }\end{array}$ & $\begin{array}{l}600 \\
\text { msec }\end{array}$ & $\begin{array}{l}750 \\
\text { msec }\end{array}$ & $\begin{array}{l}900 \\
\text { msec }\end{array}$ & $\begin{array}{l}1050 \\
\text { msec }\end{array}$ \\
\hline Simple & 0,39 & 0,23 & 0,20 & 0,17 & 0,11 & 0,07 & 0,04 \\
\hline Complex & 0,49 & 0,42 & 0,39 & 0,20 & 0,31 & 0,27 & 0,31 \\
\hline
\end{tabular}

It was established by means of log-linear analysis of the data that the main effects of the factors "Task difficulty" and "Presentation period" became statistically significant. We also found a significant difference between the simple and the complex conditions during all the presentation periods.

\subsection{Simple vs. complex samples - subject-paced reading}

In an other experiment $(n=25)$ the occlusion technique was investigated by enabling the subjects to determine the reading time necessary for solving the task themselves. The same procedure and the same stimulus material as in experiment 1 were used. The task for the simple condition was again to find the path connecting $A$ to B or to decide which of two ways was the shortest connection between A and B. Reading time and the number of correct tasks were used as a dependent variables.

We found that significantly fewer tasks were solved correctly during the complex conditions than during the simple conditions, even if subjects could spend as much reading time as they wanted to. For further analysis, only trials with correctly solved tasks were considered. There was again a significant difference between the simple and the complex condition.

\subsection{Dialogue interruption without secondary task (graphic coding)}

A second requirement for an evaluation tool implies that it discriminates between interfaces that facilitate or that hinder continuation of a dialogue after interruption. To investigate this requirement the following procedure was used: Subjects had to solve a search task on a monitor and were interrupted several times. A simple and a complex version were again compiled. In the simple version, continuation after interruption was simplified by the fact that the information to be looked for was to be found in a predictable place on the display after each interruption. In the complex version, on the other hand, the entry to be searched for could also appear at an unpredictable point on the display.

Stylised telephone charts (displays) were used as stimuli. Each stimulus contained a vertical list of five names with the corresponding telephone numbers. One of these names had a box around it. This basic type was varied a total of four times so the name in the box could be in any of the five positions. The subjects $(\mathrm{n}=$ 60 ) had to determine the name in the box and the corresponding telephone number. 
The displays were shown to the subjects a total of three times in succession; each presentation lasted 200, 300 or $400 \mathrm{~ms}$, depending on the condition. After every presentation had been masked off the monitor remained black for $500 \mathrm{~ms}$. In the simple condition, the position of the name to be found was predictable after every interruption (the change of position followed a clear pattern), during the complex condition, the position of the entry to be found varied between all positions at random. After the third presentation, the subjects had to state the name being searched for and the corresponding phone number.

The average probability of errors is displayed in Figure 2. ANOVA showed significant main effects of the factors "complexity" $(F=1,848.15, p<.00)$ and "duration of presentation" $(F=2,025.36, p<.00)$. The interaction effect was not significant $(F=61.25, p=.27)$. This means that the probability of errors in the simple condition is always lower than in the complex condition and that the longer the presentation period, the fewer the errors that are generally made.

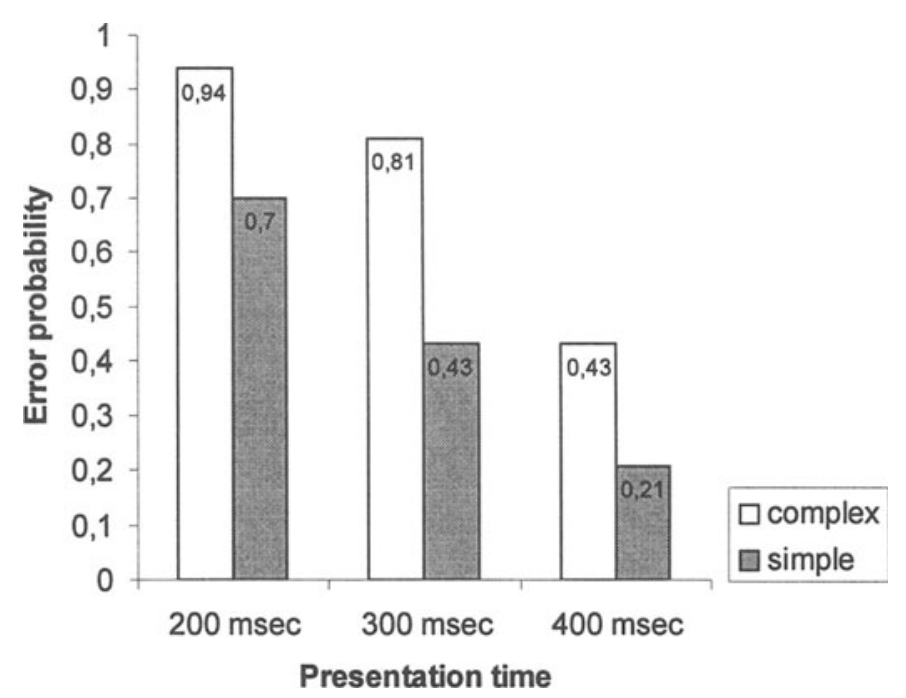

Figure 2: Probability of errors in simple and complex conditions.

\subsection{Dialogue interruption with secondary task}

In the third experiment, target information was coded graphically and no secondary task had to be processed. In an additional experiment, subjects got no graphical hints when they had to search for a pattern on a monitor and a secondary task was introduced. 30 subjects participated in this experiment. The procedure was the same as in the experiments above. The same telephone charts were used as displays as in experiment 3 but without the box around one entry.

Also the task was essentially the same as in the third experiment. The difference from experiment 3 was that the subjects were shown a name, whereupon they had to read the associated phone number on the display. The task in this experiment 
consequently involved more search and pattern matching. As in experiment 3 , there was a simple dialog condition in which the position of the information to be found changed according to a fixed scheme after the interruption, and also a complex condition where the position changed randomly. Furthermore, a secondary task had to be performed during the interruption. The secondary task also involved visual search: from four letters displayed in the corners of the monitor, the vowel had to be determined, the three other letters being consonants. The secondary task was designed in such a way that the subjects had to make an eye movement in order to solve the tasks. The telephone charts were presented three times for one second each, so that the secondary task had to be performed twice each time with a new letter presented for one second each. The phone number to be found and the two vowels had to be recalled to the testers at the end of each run.

A single-factor between-subjects design was realized. The position change of the information (fixed pattern $=$ simple condition; random change $=$ complex condition) was manipulated as an independent variable. The numbers of errors in the first and secondary tasks were defined as dependent variable.

As in experiment 3 , we found that the occlusion technique differentiates successfully between simple and complex dialogues in the case of a task that is more or less semantically coded (with a secondary task). The differences in the probability of errors for the simple condition and the complex condition are significant. Significant differences between the probabilities of errors in the secondary task were also found. For the complex condition, the probability of errors in the secondary task is much higher than in the simple condition.

\section{SUMMARY AND DISCUSSION}

The results of the experiments presented here demonstrate that the occlusion technique is a valid procedure for evaluating displays. As proved in experiments one and two, it makes a valid distinction between display designs of varying complexity. In Experiment 1, the time period (200 to $1000 \mathrm{~ms}$ ) that Zwahlen, Adams and DeBald (1988) considered acceptable for taking the eyes off the road was covered.

We also succeeded in distinguishing between simple and complex displays when using the observation periods chosen by the subjects.

The experiments concerning dialogue interruptions or the difficulty of continuing the dialogue after an interruption also showed that the occlusion technique is suitable as a simple evaluation tool. Both experiments show a significant separation between continuation situations of varying complexity. Furthermore, experiment 4 demonstrated that complex conditions had a negative influence on the secondary task. The equivalent to an actual situation in a vehicle would be that a display that makes it difficult to continue the dialog has a negative effect on the actual driving task (in our case the secondary task). The occlusion technique thus provides an important indication as to which displays make continuation of the dialogue after an interruption harder or easier and which displays can lead to greater interference with the secondary task. We consider this as important, since biased distribution of attention away from the road and toward to the display is considered a decisive safety risk (see Dewar, 1988). 
Our investigations show that the occlusion technique can be a valid procedure for evaluating display concepts and dialog interruptions. In a next step the technique also has to be tested outside the laboratory. Further investigation is needed, particularly in the dialog interruption area. So far, the only criterion for dialog interruption was how easy it was to continue the dialog afterwards. Other factors could not be considered within the framework of investigations conducted up to now. Another aspect not considered is the inclusion of differential factors in this connection. This would make allowance not only for the change in the age structure of car drivers (e.g. Pfafferott, 1994) but also diminished ability to perform visual search and selective attention tasks.

\section{REFERENCES}

Antin, JF. Informational Aspects of Car Design: Navigation. In Automotive Ergonomics (pp. 321-337), B. Peacock, W. Karwowski eds. London, Washington, DC: Taylor and Francis, 1993.

Ashby, MC, Parkes, AM. Interface Design for Navigation and Guidance. In Driving Future Vehicles, A.M. Parkes, S. Franzen, eds. London, Washington, DC: Taylor and Francis, 1993.

Dewar, RE. In-vehicle Information and Driver Overload. International Journal of Vehicle Design 1988; 9: 557-564.

Europaische Kommission (European Commission). Telematikanwendungen fur Verkehr und Umwelt: Europaischer Grundsatzkatalog zur Mensch-Maschine-Schnittstelle (HMI) fur On-Board-Informationsund Kommunikationssysteme. (Telematics Applications for Traffic and the Environment: European Catalogue of Principles Concerning the Human Being-Machine Interface for On-board Information and Communication Systems); Task Force HMI, 1988.

Färber, B. Mehr Instrumente, mehr Sicherheit? (Do more Instruments Increase Safety?). VDI Berichte 1990; 819:1-18.

Gelau, C, Keinath, A., Baumann, M, Bengler, K, Krems, JF. Die Okklusionsmethode als Verfahren zur Bewertung von visuellen Displaydarstellungen in Kraftfahrzeugen. (Occlusion as a Technique for Evaluating Visual Display Designs in Vehicles). Zeitschrift fur Arbeitswissenschaft 1999; 53: 41-57.

Helander, MG. Design of Visual Displays. In Handbook of Human Factors, G.S. Salvendy, ed. New York etc.: John Wiley, 1987.

Kantowitz, BH, Sorkin, RD. Human Factors. New York etc.: John Wiley, 1983.

Keinath, A, Baumann, M, Gelau, C, Krems, JF. Validierung von Okklusionsverfahren als Methode zur Evaluierung von Informationsdarstellungen. Bericht im Rahmen des Projektes "Validierung von Okklusionsverfahren als Verfahren zur Evaluierung von fahrtgeeigneten Informationsdarstellungen" im Auftrag der BMW AG, Munchen (Validation of Occlusion Procedures as a Technique for Evaluating Information Displays. Report within the framework of the project "Validation of Occlusion Procedures as a Technique for Evaluating Information Displays Suitable for Driving" commissioned by BMW AG, Munich. Chemnitz Technical University.). Technische Universităt Chemnitz, 1998.

Krems, JF, Keinath, A., Baumann, M., Bengler, K. \& Gelau, C. Die Bewertung von visuellen Displaydarstellungen in Kraftfahrzeugen: Vor- und Nachteile der Okklusionsmethode. In Bundesanstalt fur Straßenwesen (Hrsg.), Informations- und Assistenzsysteme im Auto benutzergerecht gestalten.

(S. 25-32). Bergisch Gladbach: Wirtschaftsverlag, 2000.

Leiser, R. Driver-vehicle Interface: Dialogue Design for Voice Input. In Driving Future Vehicles, A.M. Parkes, S. Franzen, eds. London, Washington, DC: Taylor and Francis, 1993. 
Pfafferott, I. Mobilitătsbedurfnisse und Unfallverwicklung alterer Autofahrer/innen. (Mobility Requirements and Accident Involvement of Elderly Car Drivers). In Autofahren im Alter (Elderly Car Drivers), U. Trănkle ed. Köln: Verlag TÜV Rheinland, 1994.

Sleight, RB. The Effect of Instrument Dial Shape on Legibility. Journal of Applied Psychology, 1948; 32: 170-188.

Wierwille, WW. Visual and Manual Demands of In-car Controls and Displays. In Automotive Ergonomics, B. Peach, W. Karwowski, eds. London: Taylor and Francis, 1993.

Woodson, WE, Tillmann B, Tillmann, P. Human factors design Handbook (2nd ed.). New York etc.: McGraw Hill, 1992.

Zwahlen, HT, Adams, CC JR, DeBald, DP. Safety Aspects of CRT Touch Panel Controls in Automobiles. In Vision in Vehicles - II, A.G. Gale, M.H. Freeman, C.M. Haslegrave, P. Smith, S.P. Taylor, eds. Amsterdam etc: Elsevier, 1988. 